\title{
HUBUNGAN TINGGI BADAN DAN PANJANG ULNA PADA ETNIS SANGIHE DEWASA DI MADIDIR URE
}

\author{
${ }^{1}$ Briando S. Honandar \\ ${ }^{2}$ George N. Tanudjaja \\ ${ }^{2}$ Martha M. Kaseke \\ ${ }^{1}$ Kandidat Skripsi Fakultas Kedokteran Universitas Sam Ratulangi manado \\ ${ }^{2}$ Bagian Anatomi - Histologi Fakultas Kedokteran Universitas Sam Ratulangi Manado \\ Email: b_07_10@yahoo.com
}

\begin{abstract}
Identification is an important examination to identify a person's identity. Height estimation is one of the parameter in forensic anthropology to determine a person's biological profile. Height can be estimated by measurements of long bones, including ulna. This study aimed to determine the correlation between heights and ulnar lengths among Sangihe adults in Madidir Ure. This was an analytical descriptive study with a crosssectional design. Samples were obtained with purposive sampling method and data were analyzed with Pearson correlation and simple linear regression. There were 94 subjects consisting of 56 males and 38 females. The results showed a strong correlation between height and ulnar length, with a value of (r) 0.853 in total subjects, 0.661 in males, and 0,671 in females. Equations based from the result of simple linear regression were height $=87.436$ $+2.990 \times$ ulnar length for males; height $=69.843+3.550 \times$ ulnar length for females; and height $=58.346+4.098 \times$ ulnar length for the total subjects with $P$ value $=0.000(<0.01)$. Conclusion: There was a highly significant correlation between heights and ulnar lengths among Sangihe adults in Madidir Ure.
\end{abstract}

Keywords: identification, height, ulnar length, Sangihe, adults

\begin{abstract}
Abstrak: Penentuan identitas merupakan pemeriksaan penting untuk mengidentifikasi seseorang. Pengukuran tinggi badan merupakan suatu parameter antropologi forensik yang dapat membantu menentukan profil biologis seseorang.Tinggi badan dapat ditentukan melalui pengukuran tulang panjang, termasuk tulang ulna. Penelitian ini bertujuan untuk menentukan hubungan tinggi badan dan panjang ulna pada dewasa etnis Sangihe di Madidir Ure. Penelitian ini merupakan penelitian deskriptif analitik dengan rancangan crosssectional. Sampel diambil dengan cara purposive sampling dan dianalisis dengan korelasi Pearson dan analisis regresi linier sederhana. Terdapat 94 orang sebagai sampel, yang terdiri dari 56 laki-laki dan 38 perempuan. Hasil penelitian memperlihatkan hubungan yang sangat bermakna antara tinggi badan dan panjang ulna dengan koefisien korelasi (r) keseluruhan 0,853, pada laki-laki 0,661, dan pada perempuan 0,671. Dari hasil analisis regresi linier sederhana didapatkan rumus TB laki-laki $=87,436+2,990 \mathrm{x}$ panjang ulna; TB perempuan $=$ $69,843+3,550$ x panjang ulna; dan secara keseluruhan $\mathrm{TB}=58,346+4,098$ x panjang ulna dengan nilai $P=0.000(<0.01)$. Simpulan: Terdapat hubungan yang sangat bermakna antara tinggi badan dan panjang ulna pada dewasa etnis Sangihe di Madidir Ure.
\end{abstract}

Kata Kunci: identifikasi, tinggi badan, panjang ulna, dewasa, Sangihe 
Pertumbuhan merupakan proses vital yang ditafsir dengan pengukuran tinggi badan dan merupakan penjumlahan dari panjang berbagai tulang yang membentuk proporsi tubuh dan total tinggi badan manusia. ${ }^{1}$ Pengukuran tinggi badan berdasarkan berbagai bagian tubuh manusia merupakan bidang yang dipelajari oleh ahli anatomi, antropologi dan forensik. ${ }^{1,2}$ Estimasi tinggi badan telah dianggap sebagaisalah satu parameter antropologi forensik dan membantu dalam membangun profil biologis seseorang.

Penentuan identitas individu dari bagian tubuh yang teramputasi menjadi sangat penting saat ini terutama seiring dengan meningkatnya frekuensi kejadian bencana alam seperti badai, gempa bumi, banjir dan musibah buatan manusia seperti serangan teroris, ledakan bom, kecelakaan masal, pembunuhan dengan mutilasi dan peperangan dimana kebanyakan korban tidak dapat diidentifikasi lagi karena terjadi kerusakan yang parah dari jenazah korban.,

Penelitian ini bertujuan untuk mengetahui hubungan antara tinggi badan dan panjang ulna serta menentukantinggi badan dengan formula regresi estimasi tinggi badandari pengukuran antropometri berdasarkan panjang ulna dan akan dilakukan pada etnis Sangihe yang sampai saat ini belum pernah dilakukan. Informasi yang didapat akan sangat berguna untuk ahli forensik, anatomi dan antropologi untuk menentukan tinggi badan dari panjang ulna terutama pada etnis Sangihe.

\section{METODE PENELITIAN}

Jenis penelitian yang dilakukan adalah jenis penelitian analitik dengan rancangan cross-sectional (potonglintang). Penelitian ini dilakukan di kelurahan Madidir Ure di kota Bitung pada bulan November 2013. Populasi dan sampel penelitian ini adalah ukuran tinggi badan dan panjang ulna dari etnis Sangihe di Madidir Ure berjumlah 94 orang yang terdiri dari 56 laki-laki dan 38 perempuan dengan pemilihan menggunakan cara Purposive Sampling. Kriteria Inklusi antara lain: Usia 21 - 55 tahun $^{5}$, tidak pernah mengalami patah tulang (punggung, kaki, tangan, leher) dan tidak memiliki kelainan genetik (tulang)

\section{Cara Pengukuran}

1. Tinggi badan

Subjek berdiri sempurna membelakangi dinding dalam posisi anatomi (telapak tangan menggantung pada sisi tubuh, kaki rapat, kepala, punggung, pantat dan tumit menyentuh dinding) pada lantai yang rata tanpa penutup kepala, alas kaki dan kepala subjek menghadap kedepan. Subjek menarik napas dalam-dalam dan pengukuran diambil dari puncak kepala(verteks) sampai tumit(os kalkaneus) dan dicatat dalam bentuk $\mathrm{cm}^{6}$

\section{Panjang ulna}

Panjang ulna diukur dari ujung proksimal olekranon sampai ujung distal prosesus stiloid dengan siku difleksikan dan tangan subjek memegangi bahu yang berseberangan. ${ }^{2}$

\section{Pengolahan dan analisis data}

Pengolahan data dan analisis data dilakukan setelah nilai tinggi badan dan panjang ulna didapatkan. Melalui data yang didapatkan, dihitung rata-rata dan simpangan baku dari variabel tinggi badan dan panjang ulna kemudian dilakukan analisis korelasi dan regresi linier.

1. Analisis korelasi

Analisis korelasi bivariat digunakan untuk mengetahui hubungan antara 2 variabel, yaitu variabel $X$ atau bebas (independent) dan variabel $\mathrm{Y}$ atau variabel terikat (dependent). Pengukuran korelasi bivariat diukur dengan menggunakan rumus korelasi Pearson r. ${ }^{7}$ Data yang diperoleh diolah dan dianalisis dengan program SPSS versi 20. 


\section{Regresi linier}

Analisis regresi linier digunakan untuk menentukan nilai suatu variabel dari variabel lain yang nilainya telah diketahui.

Rumus regresi linier sederhana yang digunakan: ${ }^{8}$

\begin{tabular}{|c|}
\hline $\mathrm{Y}=\mathrm{a}+\mathrm{bX}$ \\
$\mathrm{Y}=$ variabel terikat (tinggi badan) \\
$\mathrm{a}=$ nilai konstanta \\
$\mathrm{b}=$ koefisien regresi \\
$\mathrm{X}=$ variabel bebas (panjang ulna) \\
\hline
\end{tabular}

\section{HASIL PENELITIAN}

Tabel 1. Umur subjek penelitian
Sampel yang diambil dalam penelitian ini ialah dewasa etnis Sangihe di Madidir Ure dengan usia antara 21 - 55 tahun. Batas bawah umur diambil umur 21 tahun untuk menghindari pertumbuhan tulang yang masih berlangsung. Keseluruhan subjek penelitian berjumlah 94 orang yang terdiri dari 56 laki-laki dan 38 perempuan

Hasil penelitian Hubungan antara tinggi badan dan panjang ulna pada etnis Sangihe dewasa di Madidir Ure yang dilakukan pada tanggal 23 November 2013 didapatkan hasil sebagai berikut:

\begin{tabular}{ccccc}
\hline Jenis kelamin & N & $\begin{array}{c}\text { Usia } \\
\text { (tahun) }\end{array}$ & $\begin{array}{c}\text { Rata-rata } \\
\text { (tahun) }\end{array}$ & $\begin{array}{c}\text { Simpangan baku } \\
\text { (tahun) }\end{array}$ \\
\hline Laki-laki & 56 & $25-54$ & 41,20 & 6,829 \\
Perempuan & 38 & $23-55$ & 38,79 & 8,637 \\
Keseluruhan & 94 & $23-55$ & 40,22 & 7,660 \\
\hline
\end{tabular}

Tabel 2.Tinggi badan subjek penelitian

\begin{tabular}{ccccc}
\hline Jenis kelamin & N & $\begin{array}{c}\text { Tinggi } \\
\text { badan }(\mathrm{cm})\end{array}$ & $\begin{array}{c}\text { Rata-rata } \\
(\mathrm{cm})\end{array}$ & $\begin{array}{c}\text { Simpangan baku } \\
(\mathrm{cm})\end{array}$ \\
\hline Laki-laki & 56 & $153-179$ & 164,02 & 5,200 \\
Perempuan & 38 & $139-165$ & 151,31 & 6,143 \\
Keseluruhan & 94 & $139-179$ & 158,88 & 8,385 \\
\hline
\end{tabular}

Tabel 3. Panjang ulna kiri subjek penelitian

\begin{tabular}{ccccc}
\hline Jenis kelamin & $\mathrm{N}$ & $\begin{array}{c}\text { Ulna } \\
\text { kiri }(\mathrm{cm})\end{array}$ & $\begin{array}{c}\text { Rata-rata } \\
(\mathrm{cm})\end{array}$ & $\begin{array}{c}\text { Simpangan } \\
\text { baku(cm) }\end{array}$ \\
\hline Laki-laki & 56 & $23,1-28,1$ & 25,539 & 1,171 \\
Perempuan & 38 & $21,1-25,8$ & 22,876 & 1,144 \\
Keseluruhan & 94 & $21,1-28,1$ & 24,463 & 1,749 \\
\hline
\end{tabular}

Tabel 4. Panjang ulna kanan subjek penelitian 


\begin{tabular}{ccccc}
\hline Jenis kelamin & $\mathrm{N}$ & $\begin{array}{r}\text { Ulna kanan } \\
(\mathrm{cm})\end{array}$ & $\begin{array}{c}\text { Rata-rata } \\
(\mathrm{cm})\end{array}$ & $\begin{array}{c}\text { Simpangan baku } \\
(\mathrm{cm})\end{array}$ \\
\hline Laki-laki & 56 & $23,5-28,5$ & 25,682 & 1,124 \\
Perempuan & 38 & $21,1-25,8$ & 23,016 & 1,173 \\
Keseluruhan & 94 & $21,1-28,5$ & 24,604 & 1,739 \\
\hline
\end{tabular}

Tabel 5. Panjang Ulna Kiri dan Kanan Subjek Penelitian

\begin{tabular}{ccccc}
\hline & & $\begin{array}{c}\text { Una kiri dan } \\
\text { kanan } \\
(\mathrm{cm})\end{array}$ & $\begin{array}{c}\text { Rata-rata } \\
(\mathrm{cm})\end{array}$ & $\begin{array}{c}\text { Simpangan baku } \\
(\mathrm{cm})\end{array}$ \\
\hline Laki-laki & 56 & $23,1-28,5$ & 25,611 & 1,145 \\
Perempuan & 38 & $21,1-25,8$ & 22,946 & 1,153 \\
Keseluruhan & 94 & $21,1-28,5$ & 24,534 & 1,740 \\
\hline
\end{tabular}

Tabel 6. Hubungan antara tinggi badan dan panjang ulna kiri

\begin{tabular}{cccc}
\hline Jenis kelamin & $\mathrm{N}$ & $\begin{array}{c}\text { Korelasi } \\
\text { Pearson (r) }\end{array}$ & $\mathrm{P}$ \\
\hline Laki-laki & 56 & 0,671 & $<0,01$ \\
Perempuan & 38 & 0,670 & $<0,01$ \\
Keseluruhan & 94 & 0,854 & $<0,01$ \\
\hline
\end{tabular}

Tabel 7. Hubungan antara tinggi badan dan panjang ulna kanan

\begin{tabular}{cccc}
\hline Jenis kelamin & $\mathrm{N}$ & $\begin{array}{c}\text { Korelasi } \\
\text { Pearson (r) }\end{array}$ & $\mathrm{P}$ \\
\hline Laki-laki & 56 & 0,655 & $<0,01$ \\
Perempuan & 38 & 0,674 & $<0,01$ \\
Keseluruhan & 94 & 0,853 & $<0,01$ \\
\hline
\end{tabular}

Tabel 8. Hubungan antara tinggi badan dan panjang ulna kiri dan kanan 


\begin{tabular}{cccc}
\hline Jenis kelamin & $\mathrm{N}$ & $\begin{array}{c}\text { Korelasi } \\
\text { Pearson (r) }\end{array}$ & $\mathrm{P}$ \\
\hline Laki-laki & 56 & 0,661 & $<0,01$ \\
Perempuan & 38 & 0,671 & $<0,01$ \\
Keseluruhan & 94 & 0,853 & $<0,01$ \\
\hline
\end{tabular}

\section{BAHASAN}

Sampel dalam penelitian ini ialah dewasa etnis Sangihe di Madidir Ure dengan usia antara 21 - 55 tahun. Keseluruhan subjek penelitian berjumlah 94 orang yang terdiri dari 56 laki-laki dan 38 perempuan.

Pada Tabel 1 didapatkan subjek penelitian laki-laki berusia antara 25-54 tahun dengan rata-rata $41,20 \pm 6,829$ tahun. Usia subjek penelitian perempuan pada penelitian ini antara 23-55 tahun dengan rata-rata 38,79 \pm 8,637 tahun. Secara keseluruhan Usia subjek penelitian antara 23-55 tahun dengan rata-rata 40,22 \pm 7,660 tahun.

Pada Tabel 2 didapatkan tinggi badan subjek penelitian laki-laki antara 153-179 cm dengan rata-rata 164,02 \pm 5,200 cm. Tinggi badan subjek penelitian perempuan pada penelitian ini antara 139-165 cm dengan rata-rata 151,31 \pm 6,143 cm. Secara keseluruhan tinggi badan subjek penelitian antara 139-179 cm dengan rata-rata 158,88 dan $\pm 8,385 \mathrm{~cm}$. Perbedaan tinggi badan subjek penelitian laki-laki dan perempuan pada penelitian ini adalah 13 cm.

Pada Tabel 3 didapatkan panjang ulna kiri subjek penelitian laki-laki antara 23,1-28,1 cm dengan rata-rata $25,539 \pm 1,171 \mathrm{~cm}$. Panjang ulna kiri subjek penelitian perempuan pada penelitian ini antara 21,1-25,8 cm dengan rata-rata 22,876 $\pm 1,144 \mathrm{~cm}$. Secara keseluruhan panjang ulna kiri pada penelitian ini antara 21,1-28,1 cm dengan rata-rata 24,463 $\pm 1,749 \mathrm{~cm}$. Perbedaan panjang ulna kiri subjek penelitian laki-laki dan perempuan adalah 2,66 cm.
Pada Tabel 4 didapatkan panjang ulna kanan subjek penelitian laki-laki antara 23,5-28,5 cm dengan rata-rata $25,682 \pm 1,124 \mathrm{~cm}$. Panjang ulna kanan subjek penelitian perempuan pada penelitian ini antara 21,1-25,8 cm dengan rata-rata 23,016 $\pm 1,173 \mathrm{~cm}$. Secara keseluruhan panjang ulna kanan subjek penelitian antara 28,1-28,5 cm dengan rata-rata 24,604 $\pm 1,739 \mathrm{~cm}$. Perbedaan panjang ulna kanan subjek penelitian laki-laki dan perempuan adalah $2.66 \mathrm{~cm}$.

Pada Tabel 5 didapatkan panjang ulna kiri dan kanan subjek penelitian laki-laki antara 23,1-28,5 cm dengan rata-rata 25,611 $\pm 1,145 \mathrm{~cm}$. Panjang ulna kiri dan kanan subjek penelitian perempuan pada penelitian ini antara 21,1-25,8 cm dengan rata-rata 22,946 \pm $1,153 \mathrm{~cm}$. Secara keseluruhan panjang ulna kiri dan kanan subjek penelitian antara 21,1-28,5 cm dengan rata-rata $24,534 \pm 1,740 \mathrm{~cm}$. Perbedaan panjang ulna kiri dan kanan subjek penelitian laki-laki dan perempuan adalah 2.66 cm.

Hasil penelitian pada Tabel 2 jika dihubungkan dengan Tabel 3, 4 dan 5 didapatkan perbandingan lurus antara tinggi badan dan panjang ulna. Sehingga dapat disimpulkan bahwa semakin besar panjang ulna maka tinggi badan akan semakin besar.

Dari seluruh data yang didapatkan pada penelitian, dilakukan regresi linier antara tinggi badan dengan panjang ulna kiri dan kanan pada laki-laki, perempuan dan seluruh subjek penelitian menggunakan rumus regresi linier sederhana: 


\begin{tabular}{|c|}
\hline $\mathrm{Y}=\mathrm{a}+\mathrm{bX}$ \\
$\mathrm{Y}=$ variabel terikat \\
(tinggi badan) \\
$\mathrm{a}=$ nilai konstanta \\
$\mathrm{b}=$ koefisien regresi \\
$\mathrm{X}=$ variabel bebas \\
(panjang ulna)
\end{tabular}

Pada analisis korelasi, nilai $\mathrm{P}$ yang diperoleh pada seluruh subjek $\mathrm{P}=0.000$ $(<0.01)$. Dari hasil penelitian pada subjek penelitian laki-laki didapatkan koefisien korelasi (r) 0,661. Pada subjek penelitian perempuan didapatkan koefisien korelasi (r) 0,671. Pada keseluruhan subjek penelitian didapatkan koefisien korelasi (r) 0,853. Didapatkan korelasi yang kuat antara tinggi badan dan panjang ulna dari hasil penelitian.

Dari hasil analisis regresi didapatkan rumus persamaan untuk menentukan tinggi badan dengan menggunakan panjang ulna:

a. Persamaan subjek penelitian laki laki yang didapat adalah Tinggi badan $=87,436+2,990 \times$ Panjang Ulna

b. Persamaan subjek penelitian perempuan yang didapat adalah Tinggi badan $=69,843+3,550 \mathrm{x}$ Panjang Ulna

c. Persamaan keseluruhan subjek penelitian yang didapat adalah Tinggi badan $=58,346+4,098 \mathrm{x}$ Panjang Ulna

Pada penelitian ini didapatkan hasil yang positif seperti pada penelitian yang telah dilakukan sebelumnya antara lain:

Prasad et al. ${ }^{1}$ meneliti hubungan tinggi badan dan panjang ulna pada 250 Maharashtra dengan hasil $r$ pada lakilaki $=0,65, \mathrm{r}$ pada perempuan $=0,68$ dan $\mathrm{r}$ keseluruhan $=0,73$. Rumus regresi TB pada laki-laki $=93,45+2,92 \mathrm{x}$ panjang ulna, TB pada perempuan = $113,89+2,73$ x panjang ulna dan TB pada keseluruhan subjek $=132,43+$ 1,49 x panjang ulna dengan $\mathrm{P}=<0,01$
Kumar et al. $^{2}$ meneliti hubungan tinggi badan dan panjang ulna pada 300 perempuan di Bengal Barat dengan hasil $\mathrm{r}$ pada ulna kiri $=0,82$ dan pada ulna kanan $=0,67$. Rumus regresi $\mathrm{TB}=$ $45,89+4,39$ x panjang ulna kiri $\pm 7,03$ dan $\mathrm{TB}=58,72+3,89 \times$ panjang ulna kanan $\pm 9,17$. Dengan $P=<0,01$.

Simatupang $^{9}$ Meneliti hubungan tinggi badan dan radius pada 140 mahasiswa fakutas kedokteran Unsrat Angkatan 2010 dengan hasil r pada lakilaki $=0,7$, $\mathrm{r}$ pada perempuan $=0,7 \mathrm{dan} \mathrm{r}$ pada keseluruhan subjek $=0,86$. Rumus regresi TB pada laki-laki $=84+3,2 \mathrm{x}$ panjang radius, $\mathrm{TB}$ pada perempuan $=$ $56+4,1 \times$ panjang radius dan TB pada keseuruhan subjek $=38,4+4,8 \mathrm{x}$ panjang radius. Dengan $\mathrm{P}=<0,01$.

Paluta $^{10}$ Meneliti hubungan tinggi badan dan panjang kaki pada 74 mahasiswa fakultas kedokteran Unsrat angkatan 2010 dengan hasil r pada lakilaki $=0,52, \mathrm{r}$ pada perempuan $=0,71$ dan $\mathrm{r}$ pada keseluruhan subjek $=0,85$. Rumus regresi $\mathrm{TB}$ pada laki-laki = $112,930+2,361 \times$ panjang kaki, TB pada perempuan $=64,241+4,223 \mathrm{x}$ panjang kaki dan TB pada keseluruhan subjek $=54,729+4,717 \mathrm{x}$ panjang kaki. Dengan $\mathrm{P}=<0,01$

Dari hasil yang didapat diatas dapat disimpulkan bahwa penggunaan tulang panjang dalam menentukan tinggi badan seseorang dapat dilakukan $(P=0.01)$ dengan $\mathrm{r}$ keseluruhan yang terendah 0,73 .

Pada penelitian ini didapatkan hubungan yang kuat antara tinggi badan dan panjang ulna dan rumus regresi linier yang dihasilkan dapat digunakan untuk menentukan tinggi badan seseorang berdasarkan panjang ulna maupun sebaliknya.

\section{KESIMPULAN}

1. Tinggi badan dapat ditentukan berdasarkan panjang ulna.

2. Terdapat hubungan yang bermakna antara tinggi badan dan panjang 
ulna pada etnis Sangihe dewasa di Madidir Ure.

\section{SARAN}

1. Perlu dilakukan penelitian dengan menggunakan bagian tulang lain yang ada pada tubuh manusia.

2. Perlu dilakukan penelitian pada etnis/ras lain yang belum pernah dilakukan sebelumnya.

\section{DAFTAR PUSTAKA}

1. Prasad A, Bhagwat VB, Porwal S, Joshi DS.Estimation of Human Stature from length of ulna in Marathwada Region of Maharashtra. Int J Biol Med Res. 2012;3(4):2337-41.

2. Mondal MK, Jana TK, Jana SG,

Roy M. Height Prediction from Ulnar length in Females: A Study in Burdwan District of West Bengal (Regression Analysis). Journal of Clinical and Diagnostic Research. 2012;6(8):1401-4.

3. Bagali MA, Ingale DI, Bagali N, Gujar N, Bennishirur WA, Atik MD, et al. Estimation of Stature from radiologically measured humerus length among Indian adults. International Journal of Current Research. 2013;5(4):91720.

4. Oladunni EA. Stature Estimation From Upper Extremity Long Bones In A Southern Nigerian Population. Australian Journal of Basic and Applied Sciences. 2013;7(7):400-3.

5. Jahari AB, Prihatini S. Risiko Osteoporosis di Indonesia. Puslitbang Gizi dan Makanan Depkes RI, Bogor. Gizi Indon 2007;30(1):1-11

6. Badan Penelitian Dan Pengembangan Kesehatan Departemen Kesehatan RI. Pedoman Pengukuran Dan Pemeriksaan. Jakarta. 2007 [cited 2013 Sep 22]. Available from : http://www.riskesdas.litbang.depke s.go.id/download/PedomanPenguk uran.pdf

7. University of West England. Pearson's Corellation Coefficient. Bristol. 2014 [cited 2014 Feb 28]. Available from : learntech.uwe. ac.uk/da/Default.aspx?pageid $=144$ 2

8. Oxford University Press.Simple Linear Regression. [cited $2014 \mathrm{Feb}$ 28] Available from : www.oxfordjournals.org/tropej/onl ine/ma_chap2.pdf

9. Simatupang RM. Korelasi Panjang Radius Dengan Tinggi Badan Pada Mahasiswa Fakultas Kedokteran Angkatan 2010.[Skripsi]. Universitas Sam Ratulangi. Manado. 2012; hal.2432.

10. Paluta RS. Hubungan Tinggi Badan Dengan Panjang Kaki Pada Mahasiswa Fakultas Kedokteran Unsrat Angkatan 2010.[Skripsi]. Universitas Sam Ratulangi. Manado.2013; hal.23-33. 